\title{
Paste and thickened tailings - myth busting and clarification
}

\author{
T.G. Fitton ATC Williams Pty Ltd, Australia \\ K.D. Seddon ATC Williams Pty Ltd, Australia
}

\begin{abstract}
It is the contention of this paper that there remains considerable confusion regarding the mechanisms and benefits of thickened tailings schemes. The terminology and interpretation of terms like 'thickened tailings' and 'paste' receive some consideration, in light of some observed contradiction in the industry. It is also noted that a number of tailings related misconceptions prevail amongst tailings practitioners. This paper attempts to clarify some of these issues, with the intention of dispelling some tailings myths.
\end{abstract}

The subject of tailings beach slope prediction is one particular topic that deserves some consideration in the interests of clarity. A large portion of this paper is devoted to this topic, which has been approached from a number of directions over the past 40 years. Various prediction methods have been presented. Some prediction methods are analytical, with no need for any flume testing. Others have relied on a deposition test in a flume. The use of different types of flumes and deposition tests, either for providing validating data or input data, has created a great deal of confusion over what works and what does not, what is relevant and what is not. There has also been further confusion created by the presentation of the results, with some workers presenting fitted data as predictions.

This paper discusses the mechanism of tailings deposition, with a view to evaluating the applicability of some of the approaches that have been presented. Various flume types and their relevance to the process are then discussed. Deposition tests and trials are also discussed in terms of the beach slopes that have been observed. Finally, some protocols are proposed for making the presentation of data more consistent and transparent.

\section{Introduction}

Currently there is a substantial amount of misconception and confusion around thickened tailings and related topics. The term 'paste' is commonly used to mean different things. It is evident that such terminology needs clarification, so that is the first issue that this paper addresses.

It has been noticed that there are many misconceptions abounding in the tailings industry surrounding the behaviour of thickened tailings and our understanding of it. Sometimes these topics become points of contention. These myths need to be dispelled. This paper sets out to do some tailings myth busting in its second section.

The myths that are challenged here are listed as follows:

- Solids concentration is a good indicator of rheological properties (across different tailings types).

- Thickening can be targeted to be to an 'absolute' solids concentration.

- Higher levels of thickening result in a better final density in the storage.

- The density achieved on a dry beach is the maximum for the storage.

- Higher levels of thickening will result in the optimum outcome.

- Water recovery at different sites can be compared without allowing for initial solids concentration, climate, and storage configuration. 
- All methods of beach slope prediction are equally valid.

Finally, the topic of tailings beach slope prediction is discussed in terms of the need for some protocols to be imposed in the publication of new beach slope models, for the sake of clarity to readers. Some suggested protocols are proposed in this section of the paper.

\section{Terminology for thickened tailings and paste}

Strictly speaking, the term 'thickened tailings' could refer to a number of products of different tailings thickening processes. However, within the tailings industry, 'thickened tailings' has previously been defined as thickener underflow with a yield stress below $200 \pm 25 \mathrm{~Pa}$ (Jewell and Fourie, 2006). This definition for thickened tailings suggests that the lower limit for thickened tailings (as opposed to unthickened tailings) is the requirement for the material to have been through a thickener. However, in the present forum of tailings practitioners, the term 'thickened tailings' is generally used in the context of storage schemes that apply Eli Robinsky's sloping beach approach (Robinsky, 1975). In order for tailings to develop such slopes it is necessary that it is thickened beyond the point of segregation, which may not necessarily be achieved with a modest amount of thickening. Indeed, most segregating tailings slurries have been through a thickener (albeit a conventional one, or perhaps a high-rate thickener), but since they are segregating, we can't call them thickened tailings slurries in the Robinsky meaning of the expression, even though they are tailings slurries that have been thickened. It is therefore suggested that the lower limit for thickened tailings should be the segregation threshold. The upper limit for thickened tailings could also be slightly refined for the purpose of clarity and practicality. The authors suggest that the $\pm 25 \mathrm{~Pa}$ tolerance on the previously published limit should be discarded. Such a limit should be considered analogous to fine gravel versus coarse sand for example, where an arbitrarily defined cut-off size defines the separation point between the two in that scenario. Furthermore, the authors question whether the 200 Pa limit would be better replaced with a whole new definition altogether, and that is the initial settled density (ISD) of the tailings. If the tailings is thickened beyond the ISD, then there will be no substantial bleed from it upon deposition. This is posed for further consideration.

Regarding the 200 Pa definition that has already been proposed, it may be possible that there is no true paste surface disposal scheme in existence, since the slurry yield stress in the Bulyanhulu project is reported at $50-100 \mathrm{~Pa}$, and the authors are not aware of any surface disposal schemes that have featured higher yield stresses.

Paste is the product of additional thickening beyond this limit, but with an upper limit defined as the operating limit of positive displacement (PD) pumps (Jewell and Fourie, 2006). Everything above this point is defined as cake. It is suggested that this upper limit for paste is subjective, since it can vary depending on the type of PD pump being considered, or the length of the pipeline downstream of the pump. Instead it is proposed that the liquid limit of the material would be a more appropriate upper bound for paste.

It is noted that the term 'paste' is often applied to any material that comes out of the bottom of a 'paste' thickener. What is interesting to note on this point is that these so-called 'paste' thickeners are generally not capable of producing slurries with yield stresses exceeding about $150 \mathrm{~Pa}$, which suggests that the name of such thickeners is misleading if the $200 \mathrm{~Pa}$ limit is observed. It is noted that most 'paste' thickeners feature 'shear thinning loops' to break down the flocs that formed in the thickener, which effectively reduces the yield stress and viscosity of the underflow material, making it easier to remove the thickener, and to pump. The tailings material just above the shearing loop might be a paste, but downstream of the loop its yield stress is generally lower than $200 \mathrm{~Pa}$, making it a thickened tailings slurry.

Is there any difference between thickened tailings and paste? Apart from an arbitrarily defined limit in terms of yield stress, paste and thickened tailings are essentially the same. 


\section{$3 \quad$ Tailings myth busting}

\subsection{Solids concentration is a good indicator of rheological properties (across different tailings types)}

This myth has been debunked many times in the literature (Sofra and Boger, 2001), and anyone carrying out rheological testing on a range of tailings types will be well aware that paste and thickened tailings of one kind at a given concentration can present rheological properties that are vastly different to another at the same concentration. Figure 1 provides some graphic illustration of this in terms of the yield stress of a number of tailings slurries of various ore types at a variety of concentrations.

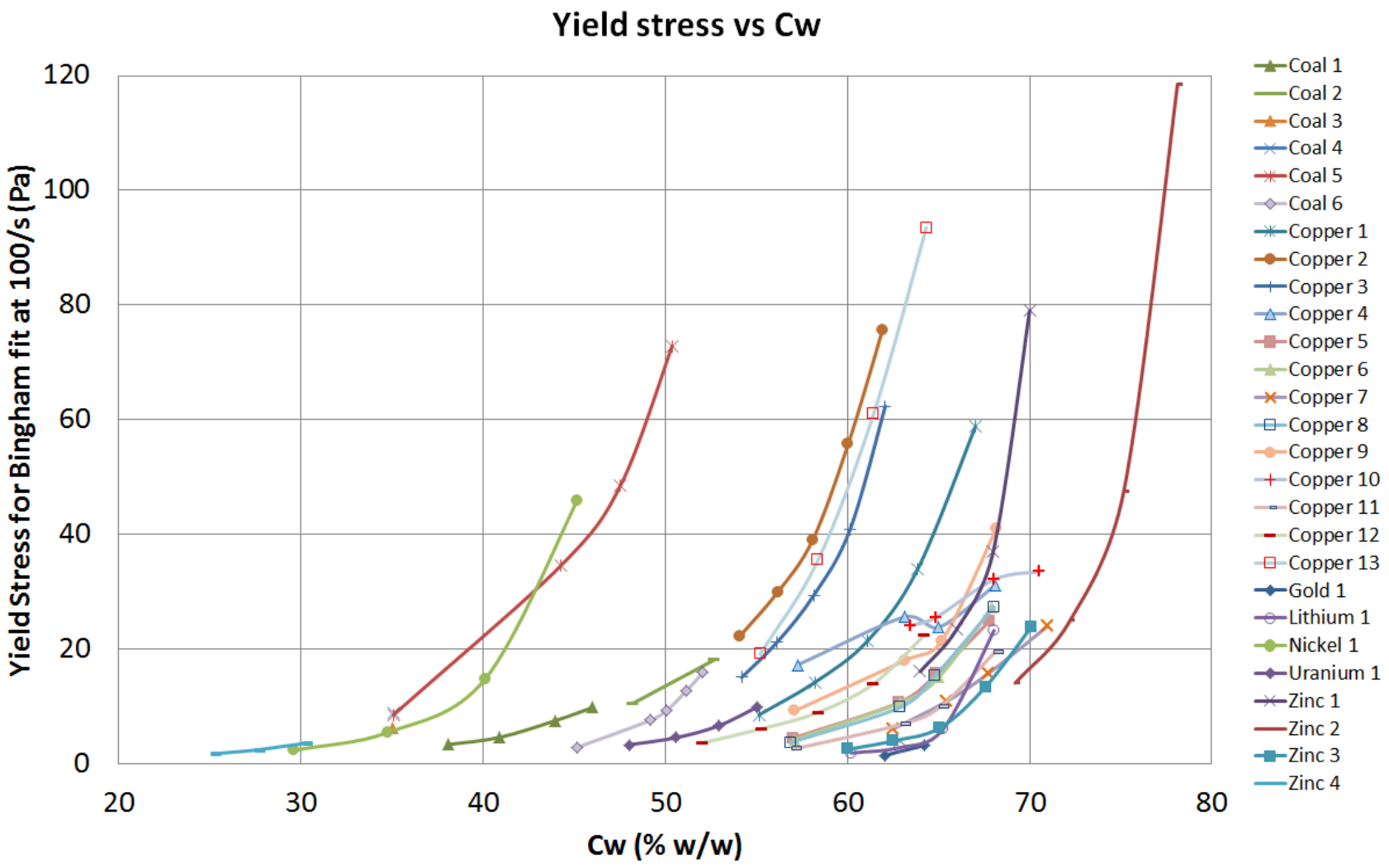

Figure 1 A plot of yield stress versus concentration for a range of tailings slurries

The plots presented in Figure 1 show the same trends as those presented by Sofra and Boger (2001). Despite this, it is found that many people in the industry still compare different slurries (in tailings storage design, pump design, beach slope, etc.) on the basis of the concentration, assuming that the same concentration means the same flow behaviour.

\subsection{Thickening can be targeted to be to an 'absolute' solids concentration}

Prior to laboratory scale testing being carried out to determine the likely performance of a thickener, it is sometimes found that engineers have a preconceived idea about what thickener underflow concentration is going to be achieved. Worse, tailings designs are sometimes prepared which rely on that particular concentration being achieved in order to meet the design requirements. Such expectations can be risky.

Once the thickener supplier has completed lab scale testing and produced a result, it is also risky to design a tailings system that relies on the thickener actually achieving the underflow densities that have been predicted in the supplier's lab. Such lab scale results are limited by the samples that are used, which may not be representative of the actual ore. Furthermore, the supplier also assumes that the operating conditions are going to be ideal, with everything operating at a uniform pace under optimum conditions. 
Such conditions are not always achieved in practice. It is therefore wise to incorporate some margin for thickener underflow shortfall in the design.

Plots of historic thickener underflow data from the Sunrise Dam gold mine and the Ernest Henry copperzinc mine are presented in Figures 2 and 3. The figures presented are the daily average underflow density, which smooths out many of the spikes that the mine would have encountered on an hourly basis, or in lesser timeframes. Despite the smoothing that has been achieved by this daily averaging of the data, a considerable amount of variation can still be seen. The performance of the thickeners at these two mines is quite uniform compared to some, though it is noted that in both cases there is a general trend for the concentration to increase over time, due to the mine operators moving to increase water recovery. Seddon and Fitton (2011) presented relevant data for a number of mines in an effort to investigate this variability, and they further proposed a design approach for thickened tailings schemes that made allowance for such variability in the slurry feed.

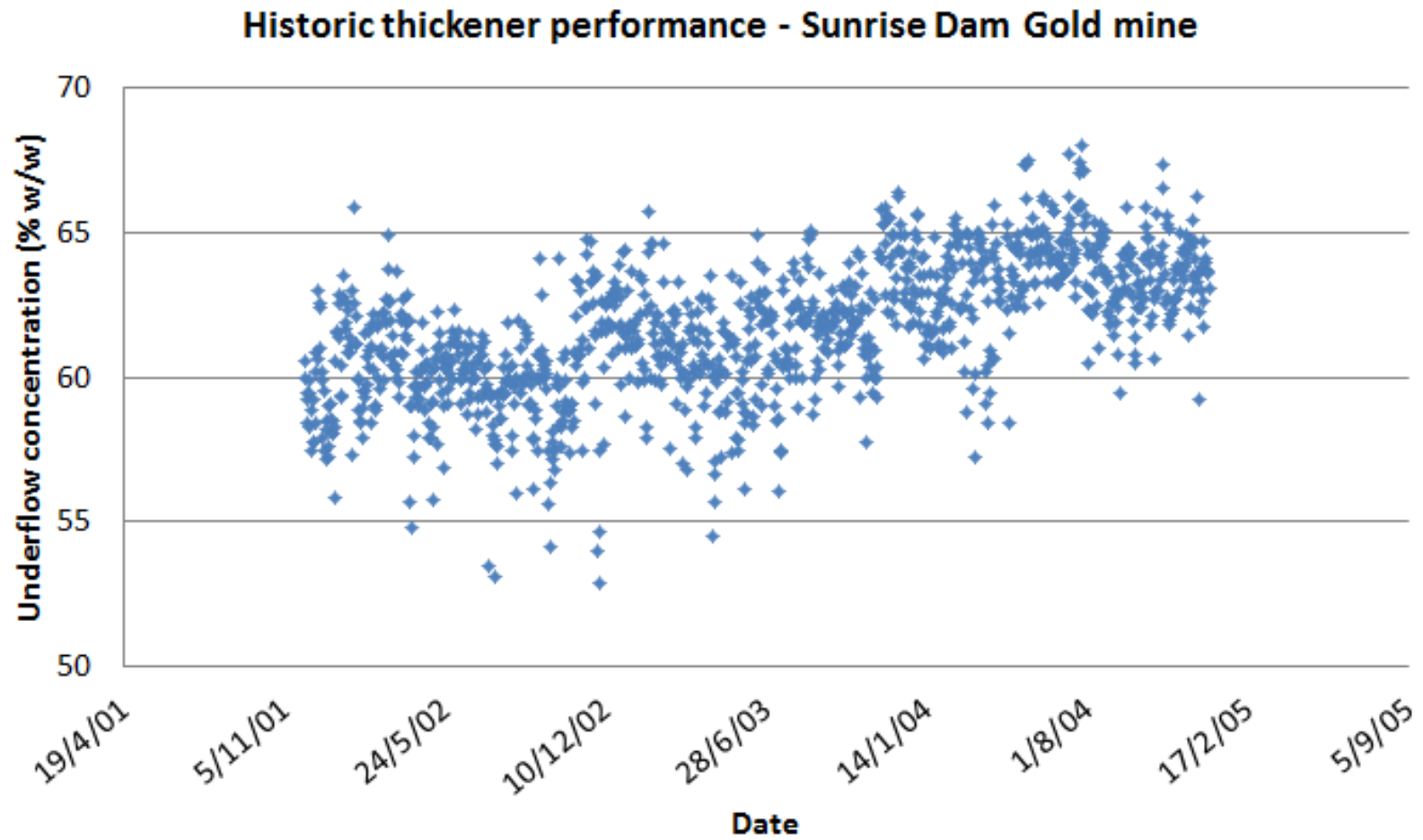

Figure 2 Historical thickener underflow data from the Sunrise Dam gold mine 


\section{Historic thickener performance - Ernest Henry Zinc-Copper mine}

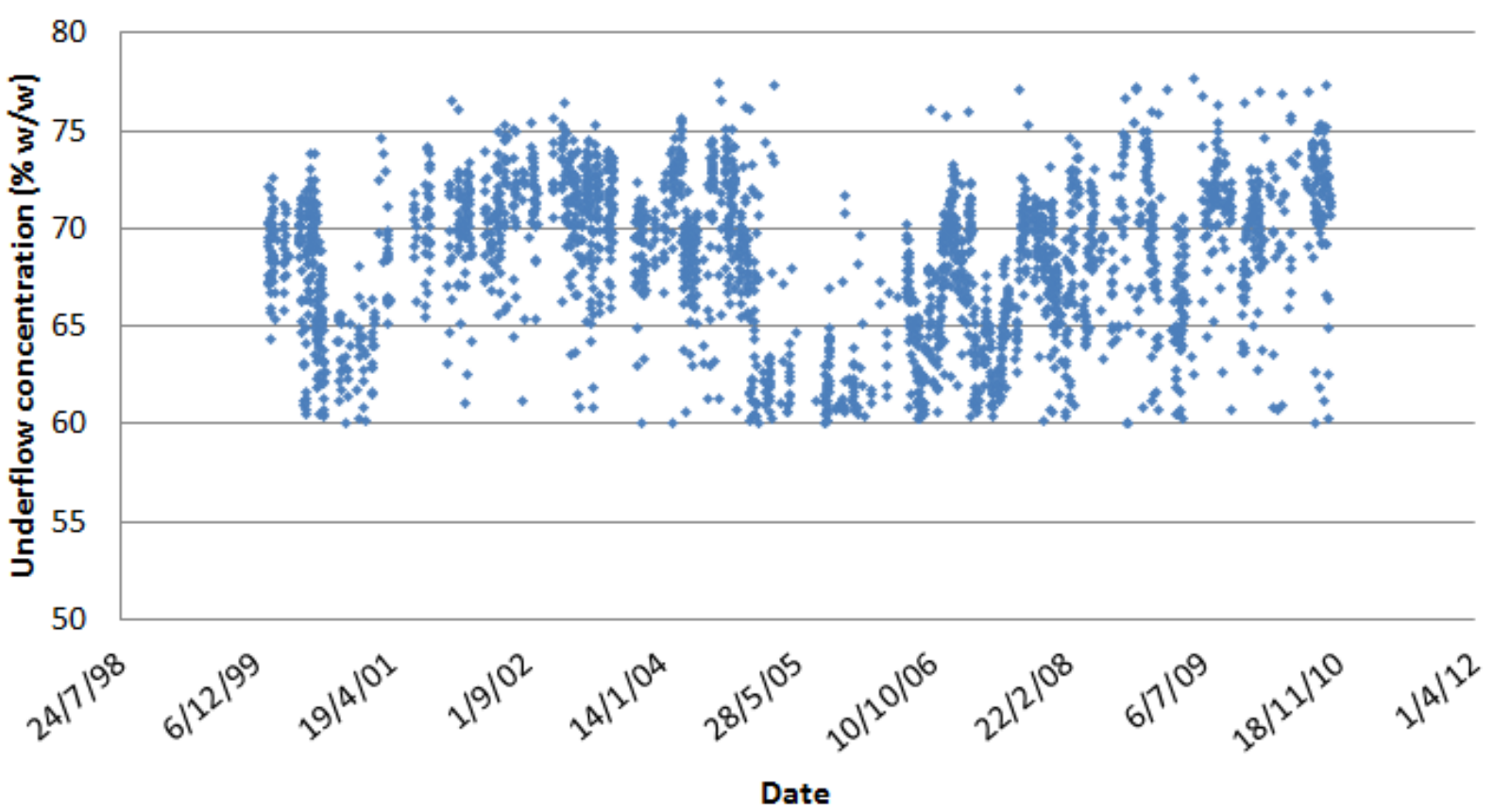

Figure 3 Historical thickener underflow data from the Ernest Henry zinc-copper mine

\subsection{Higher levels of thickening result in a better final density in the storage}

The authors have been present when the following claims have been made: 'The use of paste/high compression thickeners will result in a higher overall placement density in the storage'.

There are two parts to this, both of which are incorrect:

1. The higher initial slurry solids concentration will result in a higher ISD.

2. After settlement, there will be no further density increase in the deposit.

The first of these two claims is still hotly debated by many experts in the industry, and it is understandable for it to be so. Lab testing methods often produce results that suggest this to be the case, particularly due to the wall effects that result when using narrow measuring cylinders. Another common error is for tests to be started with the same volume of tailings being used in several containers, but with different slurry concentrations present in each. The effect of consolidation is overlooked in such tests, and with different amounts of overburden pressure present in each sample, different final densities are achieved. It is instead recommended that such tests are carried out with the same mass of tailings present in each container (i.e. different starting volumes). In the field, the somewhat rare event of a tailings slurry being discharged at different concentrations has shown that the final deposit density is much the same, despite the discharged slurry concentration being significantly different in some cases.

The second part of this issue concerns beach drying processes. In most cases, lab testing will show that the underflow density from a thickener will be lower than the ISD. The amount of time taken for tailings to reach ISD after deposition is usually expressed in hours, but may be as large as one to two days (maximum). The volume of water that runs off may vary, but the resulting tailings beach does not. At this time there is a thin layer of tailings on the beach, at a density that is independent of the concentration of the slurry it was deposited from. All subsequent drying and consolidation processes are independent of the initial slurry density.

In some rare cases the thickener can produce underflow that is denser than the ISD. This is most likely to occur with highly flocculated clayey tailings. These tailings should be expected to deposit without any significant amount of bleed water emerging, at a regularly higher density than ISD. All subsequent evaporative drying processes will commence from this improved starting point, and can proceed at a faster 
rate. This may give some overall marginal advantage in cases where the climate is such that full evaporative drying is difficult to achieve.

\subsection{The density achieved on a dry beach is the maximum for the storage}

It is often thought that the shrinkage limit density is the highest possible density that can be reached in a tailings storage facility. This is not necessarily true. The shrinkage limit is the highest density that can be achieved under the suction induced stresses resulting from evaporation and de-saturation of the tailings material. A comparison of the shrinkage limits with Rowe cell compression test results indicates that the shrinkage limit density typically falls in the pressure range of 100-200 kPa (higher for more clayey materials). These pressures will be exceeded in deposits more than 10-20 m deep (depending on the location of the phreatic surface), and higher densities will result.

\subsection{Higher levels of thickening/dewatering will result in the optimum outcome}

The optimisation objective of most tailings projects is typically to achieve a minimum whole-of-life cost for tailings storage that satisfies community and environmental constraints. The total cost of a system includes both capital and operating costs for a number of diverse sub-systems and components including thickening, tailings transport, embankment construction, land acquisition costs, closure costs, and power and water requirements. Together, these add up to a complex system. Experience has shown that there is no simple index (such as solids concentration) that will adequately represent all these inputs.

The authors quote a recent mining company representative:

"We looked at paste thickening, but it didn't work. The beach slope was too high, so we couldn't fill the storage efficiently, and we needed positive displacement pumps."

"Did you look at a reduced level of thickening?"

"Oh no, that wouldn't be as good."

It is worth noting here that true paste is generally not an optimum solution for surface mining disposal (though the use of paste thickeners to produce thickened tailings is often found to be the optimum solution). Though this point about paste been made in the past (Jewell and Fourie, 2006), it clearly needs to be restated because of the frequency of requests for paste: paste is not practical for surface disposal. Paste will ooze away from the point of discharge at slopes of about $10 \%$, creating a deposit that has steep slopes. The main problem with this is the high rate of rise and low strength that will be exhibited during the early years of operation of the TSF. Such deposits will suffer from slumping failures during this time, which will not cease until the rate of rise diminishes sufficiently for evaporation to take effect in the drying of the tailings. Another problem that must be confronted is the cost of pumping the paste to the discharge point, since the discharge point would need to be well elevated in order for the storage to contain a useful amount of tailings.

The optimum outcome can be highly dependent on the cost of water at the mine, which in turn is predominantly driven by the climatic conditions at the mine. Recent studies carried out for various dry climate mines have found that the optimum outcome can be significantly varied between thickened tailings and filter cake (Fitton and Roshdieh, 2012), depending on the cost of water. In high rainfall areas conventional tailings disposal with minimal thickening is often far cheaper than the alternatives, but other factors such as perceived safety, environmental impact, perception of technologies and political climate may become key drivers for deciding on a tailings handling and storage method.

\subsection{Water recovery at different sites can be compared without allowing for initial solids concentration, climate, and storage configuration}

Occasionally water recovery figures from TSFs at different mine sites are compared with the apparent expectation that the amount of water recovery from all TSFs should be roughly equal. This is grossly 
oversimplifying the situation, since there are a number of factors that can have a significant impact on the volume of water that collects at the decant pond in a TSF.

The rainfall and evaporation characteristics of the site are an obvious factor, which can certainly be significant. An example of this is the mining town of Rosebery on the west cost of Tasmania, which receives an annual rainfall of about $3.6 \mathrm{~m}$, with evaporation of $900 \mathrm{~mm}$ per year. This amounts to a net surplus of about $2.7 \mathrm{~m}$ per year. Conversely, Leonora in Western Australia (another mining town) receives about $250 \mathrm{~mm}$ of rainfall each year, but experiences evaporation of about $1.8 \mathrm{~m}$ per year, leaving it with a net deficit of about $1.6 \mathrm{~m}$ each year.

The solids concentration of the discharged tailings slurry can have an even greater impact on the water recovery. Consider a mine discharging tailings at $65 \%$ solids into one TSF, with another stream of tailings at $45 \%$ concentration being discharged into another TSF. The difference is $683 \mathrm{~L}$ of water per tonne of tailings being discharged.

Finally, the configuration of the storage can also have a significant impact on water recovery. The catchment area of the storage is the most obvious aspect in this regard. A TSF with a large footprint will collect a lot of rainwater in a place like Rosebery, but lose a lot of water in a place like Leonora. Conversely, a TSF with a small footprint, such as a tall turkey's nest (ring dyke) type TSF in Rosebery would minimise excess rainwater collection, whilst in Leonora, such a TSF would minimise the evaporative losses.

\subsection{All methods of beach slope prediction are equally valid.}

Broadly speaking, there are two main approaches that have been historically taken towards predicting tailings beach slopes; small-scale deposition testing and mathematical modelling.

The small-scale deposition testing approach typically sees a small deposit of tailings being created in a flume or tank (say one to five metres long), with slurry being discharged from one end ( 0.1 to $30 \mathrm{~L} / \mathrm{sec}$ ) for a reasonably short period of time (say 10 seconds to one hour) until a finite quantity of tailings ( $20 \mathrm{~L}$ to $20 \mathrm{~m}^{3}$ ) has been deposited (Blight et al., 1985; Blight, 1987; Wates et al., 1987; Boldt, 1988; Fourie, 1988; Fan and Masliyah, 1990; Kupper, 1991; Ribeiro and Assis, 1999; Sofra and Boger, 2001). In all of these cases it was found that the resultant deposit slope was not indicative of a full-scale beach slope. In more recent years larger deposition tests have been reported in narrow deposition flumes of $50 \mathrm{~m}$ length, where larger volumes of tailings were available (Engels et al., 2012). Unpublished recent trials have also been witnessed in which small-scale cones of tailings slurry have been discharged onto flat surfaces, forming mini stacks of three to ten metre diameter. Such mini stacks have been created in the past (Williams and Meynink, 1986), and have been found to be non-representative of full-scale tailings beaches. In all of these small-scale deposition tests (including the $50 \mathrm{~m}$ variety and the mini stacks) the resultant deposit slope is not indicative of a full-scale beach, but instead reveals the slumping behaviour of the slurry, and it must be concluded that direct transferral of the slopes to a full-scale deposit approach is not a valid one.

Flow-through flume testing is often confused with this small-scale deposition testing, but it does feature a key difference: flow-through flumes capture the mechanism of tailings deposition on a full-scale tailings beach (that being the channelised flow of tailings slurry across the beach surface). For this reason, flowthrough flume testing has been found to yield representative slopes when compared to the full-scale tailings beach, providing that the flow regime occurring in the flume (i.e. turbulent flow, laminar flow) can replicate that occurring in the channels on the beach (Pirouz et al., 2005; Chryss et al., 2006; Fitton, 2007).

It is noted that recent flow-through flume testing at the Chuquicamata mine (Pirouz et al., 2013) found that plug flow prevailed when the slurry exhibited a sufficiently high yield stress. This sets a new challenge for practitioners in designing storages for such thick tailings, requiring a new approach to such flow regimes. A model for predicting beach slopes when such plug flows prevail has been published recently (Fitton and Slatter, 2013).

Numerous workers have published mathematical models for the prediction of tailings beach slopes. Some of these have been theoretical (at least in part), and others have been empirical. The models with a 
theoretical basis include those of McPhail (1994), Chryss et al. (2006), Pirouz (2006), Fitton et al. (2006), Fitton (2007), Simms (2007), Li (2011) and Thomas and Fitton (2011). The purely empirical models have generally been based on correlations between slopes of real tailings beaches and other parameters (Melent'ev et al., 1973; Robinsky, 1975; Wates et al., 1987; Boldt, 1988; Pinto and Barrera, 2002). A detailed study of the models published prior to 2007 was presented by Fitton (2007), in which 16 models from the literature were applied to predict beach slopes and other relevant experimental data. It is noted that the Pirouz (2006) and McPhail (1994) models from the literature were unable to be applied at the time, due to the input parameters being impossible to derive. (It is understood that both of these methods have subsequently been modified). In that exercise it was found that the Fitton et al. (2006) model yielded better predictions than the others, but still left room for improvement. All of the other models tested in that work gave generally poor predictions. In that same work Fitton (2007) presented three new beach slope models, all of which predicted a range of relevant beach slope data quite well, and certainly more accurately than any of those tested at that time.

Simms et al. (2011) carried out a predictive test of three models from the literature; Fitton (2007), a modified form of the McPhail (1994) model; and the Simms (2007) model. It was found that the Simms (2007) model was not applicable for predicting full-scale tailings beaches, but was instead suited to predicting initial run-out of slurry in an expanding blob, as well as the local sheet flow of tailings slurry that occurs in small areas on a mature tailings beach. It was also found that the Fitton (2007) and modified McPhail (1994) models predicted reasonably well against the single beach profile that was tested, but it was agreed that more tests would be required in order to make a more general appraisal of the predictive ability of these two models.

Since 2007, a number of theoretically based new models have been presented, not all of which have yet been independently tested. It is planned that such testing will be carried out in the next year or two, hopefully to be published.

It is now well established that a valid approach to tailings beach slope prediction is to focus on the selfformed channels that run down a tailings beach. This approach has been adopted by all of the workers in this field during the last decade.

\section{$4 \quad$ Protocols for publishing beach slope prediction methods}

In recent years there has been a great deal of activity in the publication of beach slope prediction methods. Some of these published papers are misleading in their use of the word 'prediction', with models being empirically calibrated to match the slope or profile being predicted (i.e. the actual beach slope or profile is being used as an input parameter in the modelling process). Such 'predictions' should be referred to as 'fits', since the model is basically fitted to the (often limited) data to produce the right answer. A true prediction should be made without any use of the final result, and ideally, should be cast before the result is even known, so that there is no doubt of the veracity of the predictive method.

\section{$5 \quad$ A beach slope prediction test}

It is hoped that a beach slope prediction test can be staged in the near future, in which the currently available models are applied to predict beach slopes for beaches that are yet to be formed. Such an exercise will require the willingness of industry insiders who are in the planning or construction phase for a new thickened tailings scheme. Professor Andy Fourie of The University of Western Australia has recently been trying to gather this information, but it is believed that sufficient support and interest has not yet fallen behind it to bring it to fruition. Such a test will be of considerable value in ascertaining which models are genuine in their predictive capacity. 


\section{$6 \quad$ Conclusions}

This paper has attempted to dispel some of the myths that are often encountered in the tailings industry, and to clarify some topics of confusion. Some effort has also been made to propose some new terminology in the hope that it may be adopted within the industry for the sake of making certain topics clearer.

\section{Acknowledgements}

The authors would like to thank the management and staff at the sites used in this study for the provision of the base data sets. Many of the technical staff at ATC Williams have been involved in the design and ongoing monitoring of a number of these facilities, and have contributed to the data collection required for this paper. Acknowledgement is also given to the ATC Williams lab staff for the measurement of tailings data presented in this paper.

\section{References}

Blight, G.E. (1987) The concept of the master profile for tailings dam beaches, paper presented to The International Conference on Mining and Industrial Waste Management, Johannesburg, South Africa.

Blight, G.E., Thomson, R.R. and Vorster, K. (1985) Profiles of hydraulic-fill tailings beaches, and seepage through hydraulically sorted tailings, Journal of the South African Institute of Mining and Metallurgy, Vol. 85, No. 5, pp. 157-161.

Boldt, C.M.K. (1988) Beach characteristics of mine waste tailings, 9171, US Bureau of Mines.

Chryss, A.G., Fitton, T.G. and Bhattacharya, S.N. (2006) Turbulent flow of non-Newtonian tailings in self-formed channels on tailings stacks, in Proceedings Ninth International Seminar on Paste and Thickened Tailings (Paste06), R.J. Jewell, S. Lawson and P. Newman (eds), 3-7 April 2006, Limerick, Ireland, Australian Centre for Geomechanics, Perth, pp. 429-438.

Engels, J., McPhail, G.I., Jamett, R.S. and Pavissich, C. (2012) Evaluation of the behaviour of high density tailings deposition CODELCO Pilot Plant, in Proceedings 15th International Seminar on Paste and Thickened Tailings (Paste 2012), R.J. Jewell, A.B. Fourie and A. Paterson (eds), 16-19 April 2012, Sun City, South Africa, Australian Centre for Geomechanics, Perth, pp. 197-212.

Fan, X. and Masliyah, J. (1990) Laboratory investigation of beach profiles in tailings disposal, Journal of Hydraulic Engineering, Vol. 116, No. 11, pp. 1357-1373.

Fitton, T.G., Chryss, A.G. and Bhattacharya, S.N. (2006) Tailings beach slope prediction: A new rheological method, International Journal of Surface Mining, Reclamation and Environment, Vol. 20, No. 3, pp. 181-202.

Fitton, T.G. (2007) Tailings beach slope prediction, PhD thesis, RMIT University, Australia (since published as a book by VDM Verlag, Saarbrucken, Germany in 2010).

Fitton, T.G. and Roshdieh, A. (2012) The impact of slurry rheology on tailings transport and disposal options - Four case studies, paper presented at IIR Slurry Pipelines Conference 2012, 20-21 November, 2012, Perth, Australia.

Fitton, T.G. and Slatter, P.T. (2013) A tailings beach slope model featuring plug flow, in Proceedings 16th International Seminar on Paste and Thickened Tailings (Paste 2013), R.J. Jewell, A.B. Fourie, J. Caldwell and J. Pimenta (eds), 17-20 June 2013, Belo Horizonte, Brazil, Australian Centre for Geomechanics, pp. 495-506.

Fourie, A.B. (1988) Beaching and permeability properties of tailings, paper presented to Hydraulic Fill Structures, ASCE, Geotechnical Specialty Conference, 14-17 August 1988, CSU, Fort Collins, USA.

Jewell, R.J. and Fourie, A.B. (2006) Paste and Thickened Tailings - A Guide, 2nd edition, R.J. Jewell and A.B. Fourie (eds), Australian Centre for Geomechanics, Perth, Australia, 256 p.

Kupper, A.A.G. (1991) Design of hydraulic fill, PhD thesis, University of Alberta.

Li, A.L. (2011) Prediction of tailings beach slopes and tailings flow profiles, in Proceedings 14th International Seminar on Paste and Thickened Tailings (Paste2011), R.J. Jewell and A.B. Fourie (eds), 5-7 April 2011, Perth, Australia, Australian Centre for Geomechanics, Perth, pp. 307-322.

McPhail, G.I. (1994) Prediction of the beaching characteristics of hydraulically placed tailings, PhD thesis, University of Witwatersrand.

Melent'ev, B.A., Kolpashnikov, H.P. and Volnin, B.A. (1973) Alluvial hydraulically engineered constructions, Energy, Moscow.

Pinto, M. and Barrera, S. (2002) Tailings beach slope forecasting - Copper tailings, paper presented to 9th International Conference on Tailings and Mine Waste, 27-30 January 2002, Fort Collins, USA.

Pirouz, B. (2006) Beach slope forecasting, PhD thesis, K.N. Toosi University of Technology.

Pirouz, B., Kavianpour, M.R. and Williams, M. P.A. (2005) Thickened tailings beach deposition - Field observations and full-scale flume testing, in Proceedings Eighth International Seminar on Paste and Thickened Tailings (Paste05), R.J. Jewell and S. Barrera (eds), 20-22 April 2005, Santiago, Chile, Australian Centre for Geomechanics, Perth, pp. 53-72.

Pirouz, B., Seddon, K.D., Pavissich, C., Williams, P. and Echevarria, J. (2013) Flow through tilt flume testing for beach slope evaluation at Chuquicamata Mine CODELCO, Chile, in Proceedings 16th International Seminar on Paste and Thickened Tailings (Paste 2013), R.J. Jewell, A.B. Fourie, J. Caldwell and J. Pimenta (eds), 17-20 June 2013, Belo Horizonte, Brazil, Australian Centre for Geomechanics, pp. 459-474. 
Ribeiro, L.F.M. and Assis, A.P. (1999) Experimental simulation of the hydraulic deposition process in tailings dams, Masters thesis, Federal University of Ouro Preto.

Robinsky, E.I. (1975) Thickened discharge - A new approach to tailings disposal, CIM Bulletin, Vol. 68, pp. 47-53.

Seddon, K.D. and Fitton, T.G. (2011) Realistic beach slope prediction and design, in Proceedings 14th International Seminar on Paste and Thickened Tailings (Paste2011), R.J. Jewell and A.B. Fourie (eds), 5-7 April 2011, Perth, Australia, Australian Centre for Geomechanics, Perth, pp. 281-294.

Simms, P. (2007) On the relation between laboratory flume tests and deposition angles of high density tailings, in Proceedings Tenth International Seminar on Paste and Thickened Tailings (Paste07), A.B. Fourie and R.J. Jewell (eds), 13-15 March 2007, Perth, Australia, Australian Centre for Geomechanics, Perth, pp. 329-335.

Simms, P., Williams, M.P.A., Fitton, T.G. and McPhail, G. (2011) Beaching angles and evolution of stack geometry for thickened tailings: A review, in Proceedings 14th International Seminar on Paste and Thickened Tailings (Paste2011), R.J. Jewell and A.B. Fourie (eds), 5-7 April 2011, Perth, Australia, Australian Centre for Geomechanics, Perth, pp. 323-338.

Sofra, F. and Boger, D.V. (2001) Slope prediction for thickened tailings and pastes, paper presented to 8th International Conference on Tailings and Mine Waste, 15-18 January 2001, Fort Collins, USA.

Thomas, A. and Fitton, T.G. (2011) Analysis of tailings beach slopes based on slurry pipeline experience, in Proceedings 14th International Seminar on Paste and Thickened Tailings (Paste2011), R.J. Jewell and A.B. Fourie (eds), 5-7 April 2011, Perth, Australia, Australian Centre for Geomechanics, Perth, pp. 295-306.

Wates, J.A., Stevenson, C. and Purchase, A.R. (1987) The effect of relative densities on beaching angles and segregation on gold and uranium tailings dams, paper presented to International Conference on Mining and Industrial Waste Management, Johannesburg.

Williams, M.P.A. and Meynink, W.J.C. (1986) Tailings beach slopes, paper presented to Workshop on Mine Tailings Disposal, The University of Queensland. 